\title{
"Golf ball liver": agent orange hepatitis
}

\author{
C Leonard, C M Burke, C O'Keane, J S Doyle
}

\section{Department of Medicine, James Connolly Memorial the diagnosis of "golf ball liver". \\ (Gut 1997; 40: 687-688)} Hospital,

Blanchardstown, Dublin 15, Ireland C Leonard

C M Burke

Department of Pathology, Mater Misericordiae Hospital, Dublin, Ireland

C O'Keane

Department of Gastroenterology, Beaumont Hospital, Dublin, Ireland J S Doyle

Correspondence to: Dr Conor M Burke, Department of Medicine James Connolly Memorial Hospital, Blanchardstown, Dublin 15, Ireland.

Accepted for publication 23 January 1997

Keywords: hepatitis, 2,4-dichlorophenoxyacetic acid.

\section{Case report}

A 65 year old retired consultant engineer presented with a two month history of lethargy and a two week history of dark urine and upper abdominal discomfort. His family doctor diagnosed jaundice and referred him to hospital. On admission there was no history of any medication or contact with any cases of jaundice and no blood transfusions or intravenous drug misuse. He did not drink alcohol and had no history of foreign travel. He was a widower and played golf every day. Medical history was unremarkable apart from diverticulitis diagnosed one year previously when liver function tests were normal (bilirubin $12 \mu \mathrm{mol} / \mathrm{h}$,

\begin{abstract}
2,4-Dichlorophenoxyacetic acid (2,4-D) is a selective weedkiller which works by uncoupling oxidative phosphorylation and is in widespread use. It is known as "agent orange". A 65 year old man had acute hepatitis, thought to be caused by exposure to 2,4-D. The patient ingested 2,4-D as a result of habitual licking of his golf ball. Clinical and histological data together with a challenge test confirmed
\end{abstract} aspartate aminotransferase (AST) $35 \mathrm{U} / \mathrm{l}$, ala-

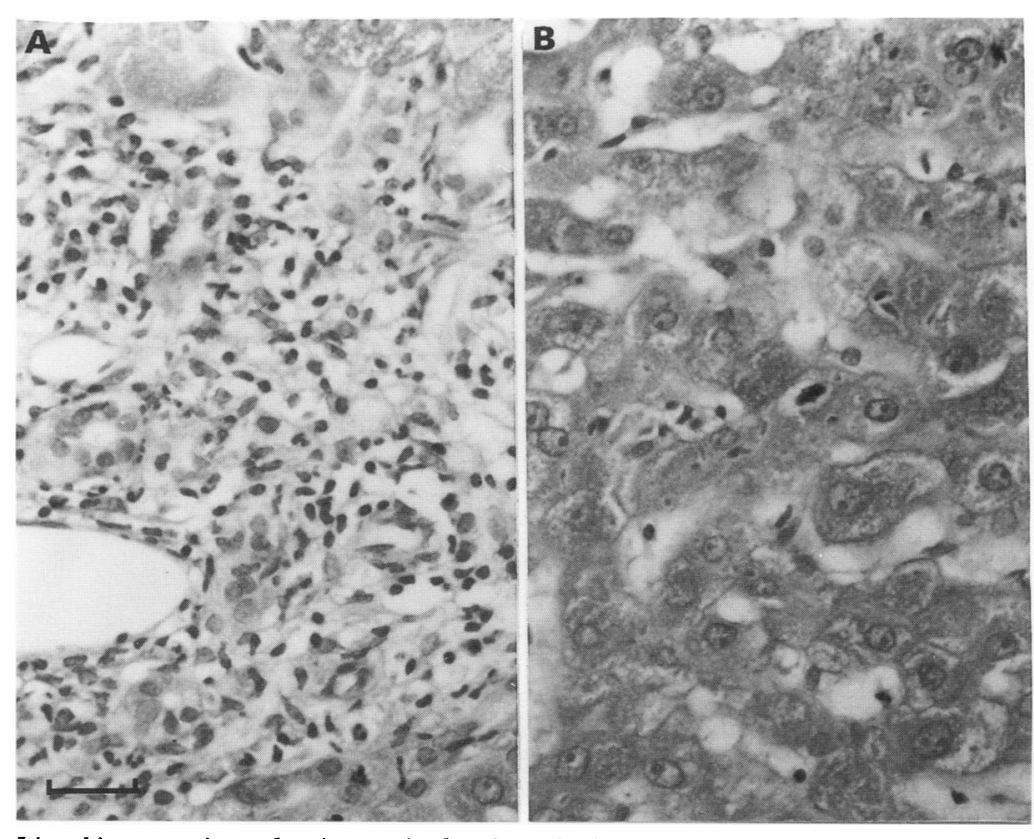

Liver biopsy specimen showing a mixed periportal $(A)$ and lobular $(B)$ inflammation. The infiltrate is composed of lymphocytes, plasma cells, and eosinophils. In addition there is intracanalicular cholestasis ( $B$, centre) and associated hepatocyte swelling (haematoxylin and eosin stain, original magnification $\times 200$, scale bar $=50 \mu \mathrm{m}$ ). nine aminotransferase (ALT) $27 \mathrm{U} / \mathrm{l}, \gamma$-glutamyl transferase $(\gamma-\mathrm{GT}) 30 \mathrm{U} / \mathrm{l}$, alkaline phosphatase (ALP) $70 \mathrm{U} / \mathrm{l})$.

Investigations including full blood count, urea and electrolytes, serum ferritin, serology screening for hepatitis $\mathrm{A}, \mathrm{B}$, and $\mathrm{C}$, herpes simplex virus, cytomegalovirus, Epstein-Barr virus, toxoplasma, and leptospirosis were all negative. Aerobic and anaerobic blood cultures were negative and urinalysis was positive for bilirubin and urobilinogen. Liver function tests were greatly raised (bilirubin $142 \mu \mathrm{mol} / \mathrm{l}, \mathrm{AST}$ $205 \mathrm{U} / \mathrm{h}, \mathrm{ALT} 380 \mathrm{U} / \mathrm{l}, \gamma$-GT $210 \mathrm{U} / \mathrm{l}$, ALP $412 \mathrm{U} / \mathrm{l})$. Liver ultrasound and abdominal computed tomography were normal. Percutaneous liver biopsy disclosed preservation of normal liver architecture with pronounced cholestasis, both canalicular and intracellular. In addition, features of an acute hepatitis were present with lobular and portal inflammation, periportal oedema, and a mixed inflammatory infiltrate, composed mostly of mononuclear cells with some eosinophils (Figure). The favoured pathological interpretation, given the mixed cholestatic-hepatitic picture with eosinophils, was a reaction to a drug or toxin. The patient denied any drug, toxin, alcohol, or dietary indiscretions.

The liver function tests showed progressive improvement over a two week period (bilirubin $50 \mu \mathrm{mol} / \mathrm{l}$, AST $84 \mathrm{U} / \mathrm{l}$, ALT $115 \mathrm{U} / 1, \gamma$-GT $76 \mathrm{U} / \mathrm{h}, \mathrm{ALP} 382 \mathrm{U} / \mathrm{l}$ ) and a provisional diagnosis of hepatitis related to a toxic reaction to an undetermined agent was made.

On returning home, having been advised of the possibility of a toxic reaction, our patient informed us that signs on the golf course advised against licking golf balls as the selective weedkiller in use, 2,4-dichlorophenoxyacetic acid $(2,4-\mathrm{D})$, was potentially toxic if ingested. $\mathrm{He}$ admitted to habitually licking his golf ball to clean it, particularly on the greens, where the greatest concentration of the weedkiller is applied. Therefore he ceased his habit and within two months his liver function tests had returned to normal and he felt well.

However, four months later he requested repeat liver function tests, which were again abnormal (bilirubin $51 \mu \mathrm{mol} / \mathrm{l}$, AST $160 \mathrm{U} / \mathrm{h}$, ALT $145 \mathrm{U} / \mathrm{l}, \gamma$-GT $120 \mathrm{U} / \mathrm{l}$, ALP $210 \mathrm{U} / \mathrm{l}$ ). $\mathrm{He}$ explained that he was sceptical of his diagnosis and when the golf course was resprayed with the weedkiller 2,4-D he resumed licking his golf ball to re-challenge himself for a month before requesting the repeat tests. The results of the tests returned to normal again one month after he ceased licking his golf ball and our patient finally accepted his diagnosis of "golf ball liver". He plays golf regularly, carries a damp cloth to clean his golf ball, and remains well to date, 
with normal liver function tests five years after his acute presentation.

\section{Discussion}

2,4-Dichlorophenoxyacetic acid is the active ingredient of the weedkiller used on the golf course. Phenoxyacids are plant hormone type compounds that cause their toxic effects by uncoupling oxidative phosphorylation and are widely used herbicides. ${ }^{1}$ Systemic toxicity in humans has been reported after ingestion, inhalation, and skin contact with these compounds. Although transient increases in liver enzymes have been reported, acute hepatitis has not been reported as a complication of 2,4-D ingestion. ${ }^{1}$

Ballantyne et al describe 2,4-D as a gastric irritant and moderately toxic, but state that in humans large doses are needed to produce major toxic effects. These include alterations in consciousness, muscle fasciculation, vomiting, and convulsions, and with gross overdose, stupor, muscle hypotonia, and coma. ${ }^{2}$ There is one documented case of suicide after ingestion of a large amount ( $>80 \mathrm{mg} / \mathrm{kg}$ ) of $2,4-\mathrm{D}$, and the cause of death was recorded as a probable ventricular arrhythmia. ${ }^{3}$

\section{Conclusion}

There seems little doubt that our patient's hepatitis was due to ingestion of 2,4-D from his golf ball. He had no other risk factors for toxic or allergic liver disease and there was no history or a rash or other hypersensitivity reaction. The large increase in liver enzymes returned to normal without any treatment, deteriorated on re-exposure to the toxin, and normalised once the exposure stopped. Furthermore, the presence of eosinophils in the inflammatory infiltrate on liver biopsy is typical of a toxin aetiology. We did consider the possibility of other causes of a toxic hepatitis apart from $2,4-\mathrm{D}$, such as the material coating the golf ball or some other fertilising agent used on the golf course, but the patient had been habitually licking the same brand of golf ball for years without adverse effects and the golf course superintendent has assured us that only 2,4-D had been sprayed on the golf course at the time in question.

Given this case, the popularity of golf, the propensity of golfers to lick their golf balls, and the widespread use of selective weedkiller on golf courses, we suggest that "golf ball liver" is a definite clinical entity and that golfers should beware.

Dr Colm Leonard is supported by a Glaxo/British Council Chevening Research Fellowship.

1 Craig SA. Herbicides and fungicides. In: Vicellio $P$, ed. Handbook of medical toxicology. Boston: Little Brown, Handbook of

2 Mans TC. Toxicology of pesticides. In: Ballantyne B, Marks $\mathrm{T}$, Turner P, eds. General and applied toxicology. Vol 2. New York: Stockton Press, 1993: 1329-41

3 Berwick P. 2,4-Dichlorophenoxyacetic acid poisoning in man, some interesting clinical and laboratory findings. fAMA 1970; 214: 87-91. 